Cardiac output

coronary blood flow

myocardial blood flow pulmonary stenosis radioactive microspheres right ventricular hypertrophy

\title{
Coronary Reserve and Right Ventricular Function in Awake Newborn Lambs with Persistent Right Ventricular Hypertension
}

\author{
JOSEPH P. ARCHII, JR., (2" DAVID E. FIXLER, AND JULIFN I. E. HOFFMAN
}

Cardiov'ascular Rese'ach Institute, University of California in San Francisco, San Francisco, California, USA

\begin{abstract}
Summary
Right ventricular function curves as measured by right ventricular stroke work were normal in all control lambs, whereas three of five lambs with banded pulmonary arteries had relatively flat curves. I.eft ventricular function was similarly normal in the control group as compared to a near zero slope function curve in the banded group. Regional myocardial blood flow to the septum and right and left ventricles was similar in control and banded lambs. At rest right ventricular coronary vascular resistance was lower in the banded than in the control group and decreased in both groups during both isoproterenol and dextran stress states. In general, both groups had a similar ratio of right to left ventricular oxygen supply to demand ratio. These results show first that there is minimal, if any, biventricular functional
\end{abstract}

reserve in lambs with persistent right ventricular hypertension, and second, that there is substantial coronary vascular reserve in both normal and banded groups.

\section{Speculation}

Although both right and left ventricular function are impaired in neonatal lambs with persistent right ventricular hypertension, the etiology is unclear. We have demonstrated right ventricular coronary vascular reserve in this group; however, we did not test for further reserve in the dextran stress state, and therefore camnot be certain that coronary blood now was not maximal in the dextran state and hence ventricular function impaired by inadequate oxygen supply. 


\section{NTRODUCTIO:}

During fetal life right and left ventricular systolic pressures are similar. Normally after birth right ventricular pressure decreases when pulmonary vascular resistance falls and the ductus arterious closes. However, right ventricular systolic hypertension may persist in a number of congenital cardia defects and in neonatal pulmonary disease. In adult animals acute elevation of right ventricular systolic pressures to left ventricular levels is poorly
tolerated $(3,6,10)$, one explanation for which is inadequate right ventricular coronary blood flow $(3,6,10,15,16)$. By contrast, the tolerance for increased right ventricular pressures in the early neonatal period may be due to greater

Although the normal newborn lamb heart has left ventricular function qualitatively similar to the adult (8), evidence of left ventricular coronary vascular reserve (8). a tolerance to hypoxia (15), and adequate response to positive inotropic agents (9). right ventricular functional reserve and coronary blood flow in normal newborn mammals and in those with right ventricular have impaired right ventricular function (1i). we have previously shown that have impaired right ventricular function (11). we have previously shown that five to twelve week old lambs with persistent $r$ ight ventricular hypertension
created by pulmonary artery banding at two days of age have right ventricular hypertrophy, nomal ventricular end diastolic pressures, and higher than normal hypertrophy, nomial ventricular end diastolic pressures, and higher than norma
right ventricular coronary blood flow both at rest and when stressed (2). We right ventricular coronary blood flow both at rest and when stressed (2). We
hypothesized that right ventricular function and coronary blood flow may be hypothesized that right ventricular function and coronary blood flow may be
adequate in neonatal lambs early after pulmonary artery banding since elevated adequate in neonatal lambs early after pulmonary artery banding since elevated
right ventricular afterload is a continuation of the prenatal state. Accordingly. we studied right ventricular functional reserve and coronary flow during ingly. We studied right ventricular functional reserve and coronary flow during
the first 18 days of 1 ife in awake control and banded lambs at rest and during isoproterenol and dextran infusion stresses.

\section{METHODS}

Ten lambs were operated upon twenty-four to forty-eight hours after birth. They were premedicated with $5 \mathrm{mg}$ of diazepam (ValiumR), given $5 \mathrm{mg}$ methohexital by a volume controlled respirator with a mixture of 50 : nitrous oxide and $50^{\circ}$ oxygen containing l: halothane. Under sterile conditions, a left thoracotom was made in the fourth intercostal space and the ductus arteriosus ligated. polyvinyl catheters (No. 5F) were placed in the internal mamary artery and vein, the left atrium via a pulmonary vein branch. the left pulmonary artery via a left upper lobe pulmonary artery branch, and the aorta through a purse string suture. A catheter (No. $5 \mathrm{~F}$ end hole) was placed through a purse string in the outflow tract of the right ventricle. In five lanbs we passed an umbilical tape around the main pulmonary artery and created a stenosis by tightening the tape. We used either a peak systolic right ventricular pressure of mia, or a significant decrease in aortic pressure, whichever occurred first. as an end point in narrowing the pulmonary artery. The tape was then tied and the chest closed. Five control larbs had identical operative procedures but for the placement of the pulmonary artery tape. The pericardium was left open in all animals and a chest tube was used for several hours to insure full lung expansion. Catheters were brought out through percutaneous stab wounds in the
back and were flushed daily with dilute heparinized saline.

All lambs were studied at five to eighteen days after birth. They were given only liquids the night prior to study. The next day they were loosely restrained on a table. Pressures were monitored with Statham $P-230 b$ pressure transducers with zero pressure set at the mid chest and recorded on an eight
channel Beckman ink oscillograph. We used the radioactive microsphere method channel Beckman ink oscillograph. We used the radioactive microsphere method Filtered microspheres of 4-12 micron diameter (mean 7) labeled with ${ }^{14 i} \mathrm{Ce}$, ${ }^{85} \mathrm{Sr},{ }^{46} \mathrm{SC}$, and 15 micron diameter 125, labeled spheres were used. For each measurement approximately 4 to $5 \times 10^{5}$ microspheres suspended in two milliliters of $0.5 i$ Tween were injected into the left atrium with 10cc of body temperature saline over 45 seconds. The method of preparation and injection o
microspheres, and collection of arterial reference samples has been described $(1,4)$.

Pressures, cardiac output, and myocardial blood flow were measured in each res sure and heart rate had been stable for approximately five minutes. The isoproterenol infusion was then stopped, the lambs allowed to rest for ten to fifteen minutes until the heart rate and pressures had returned to pre isoproterenol infusion values. A slow infusion of Dextran 70 was then begun and per kilogram had been infused. Usually measurements were made at two left atrial pressures in this state. Because 15 micron diameter spheres may not measure transmural myocardial blood flow distribution as accurately as the filtered 4 to 12 micron diameter spheres and not as many can be given. the

hie killed the lamb with intravenous barbiturate and removed the heart. The atrial septum was inspected for patency of the foramen ovale. The large coronary arteries, great vessels and fat were removed from the heart. The dissected from the ventricles and from each other. The free wall of the right ventricle was cut away from the left ventricle and both were dissected into four layers of approximately equal thickness. The myocardial layers were weighed, placed in vials, and the garma radioactivity counted. After counting, the right ventricles of all lambs were dried at $1100 \mathrm{C}$ for 48 hours and re-
weighed. All animals were examined for pleural effusion, ascites, and hepatoweighed.
megaly.

Traditionally, right ventricular coronary vascular resistance is calculated by dividing the difference between mean aortic and right atrial pressure by right ventricular coronary blood flow. Here, right ventricular coronary vascular resistance per unit weight was calculated using the pressure index
$(2,10)$ as the driving pressure; the pressure index is the integrated difference $(2,10)$ as the driving pressure; the pressure index is the integrated difference
per minute between aortic and right ventricular pressures (10). The reason for per minute between aortic and right ventricular pressures $(10)$. The reason for
using the pressure index instead of aortic pressure is because right ventricular chamber pressure may be transmitted into the ventricular wall and act as a
starling resistor on the coronary vascular bed.

We calculated an index of peak ventricular wall stress $(\tau)$ by multiplying peak ventricular pressure by the ratio of ventricular free wall weight to body
weight $\left(\tau=\mathrm{P} \times W_{V} / W_{B}\right)(2)$. The adequacy of myocardial oxygen delivery was estimated by calculating the ratio of right to left ventricular oxygen delivery
per unit peak systolic wall stress (2). This ratio removes variables comon to both ventricles such as heart rate and arterial blood oxygen content, and
accordingly, contains only right and left ventricular flow, peak systolic sure and weight (from the wall stress calculation). The normalized distribu- tion of flow within the sub regions of the right and left ventricle and septum was computed by dividing the flow per unit weight of each sub region by flow per unit weight of each region. This gives
flow for each region at each state studied.

\section{RESULTS}

The age at time of study, body weight, measured pressures and flows in the resting, isoproterenol and two dextran states for the five control and five banded lambs are given in Table I. Control lamb number 1 was studied only in the resting state because of technical problems. The ratio of right ventricular dry to wet weight was similar in the control and banded groups, 0.149 * 0.0057 and $0.152: 0.0055$ (mean $=1$ standard deviations of mean) respectively.
None of the lambs had a patent foramen ovale, pleural effusion or ascites. None of the lambs had a patent foramen oval
Banded lanb number 2 had an enlarged liver.

Figure 1 shows the ratio of right ventricular free wall weight to total body weight for both groups as a function of age. In general, the banded lambs tended to maintain a constant right ventricular weight to total body weight a similar group of banded lambs studied at approximately sixty days of age (2). Conversely, this weight ratio decreased in the control group and approached the value seen at sixty days in normal lambs (2).

Right ventricular function as measured by right ventricular stroke work per $\mathrm{kg}$ body weight and mean right atrial pressure is depicted in rigure 2 . Three studies were made in most lambs, the control and the two dextran infusion curves as compared to the relatively flat right ventricular function curves curves as compared to the relatively flat right ventricular function curves
three of five banded lambs. Lamb number 2 in the banded group probably had right ventricular failure at rest because of the high right atrial pressure and because stroke work decreased as right atrial pressure increased.

Left ventricular function as measured by left ventricular stroke work per $\mathrm{kg}$ of body weight and mean left atrial pressure is shown in Figure 3. In banded iambs and positive in the control group. Lamb number 2 in the banded group had marked left ventricular faflure at rest as evidenced by a resting

The regional distribution of myocardial blood flow to right ventricular free wall, septum and left ventricular free wall in the resting. isoprotereno and dextran states is shown in Figure 4 . With the exception of banded lamb number 2, who was in biventricular fallure, myocardial blood flow per gram to the septum and left ventricle was not very different in the two groups in the resting state. However, right ventricular flow was significantiy higher at
rest in the banded group ( $<<0.05$, by the Mann-whitney $u$ test) rest in the banded group ( $p<0.05$, by the Mann-Whitney $U$ test). In the isoproterenol and dextran stress states, no appreciable differences in flow could be demonstrated except that the control group tended to have higher regional the regional blood flows in sixty day old control lambs (2) Right ventricular free wall coronary vascular resistance is given in
figure 5 for the resting, isoproterenol and dextran states as a function of age. In the resting state, right ventricular coronary vascular resistance was lower in the banded group than in the control group. This difference was
similar to that seen in the older lambs (2). The control lambs in the isoproterenol and dextran states tended to have a lower right ventricular coronary vascular resistance than the older lamibs (significant at $p<0.01$ for dextran by unpaired $t$ test). Right ventricular coronary resistance in the banded lambs in the isoproterenol and dextran states was not different from values reported
in oider banded lambs (2).

The ratio of right to left ventricular oxygen delivery per unit peak systolic wall stress (2) is given in Figure 6 for the resting and two stres states as a function of age. In general, both the banded and control lambs
tended to have a sinilar supply to demand ratio over the thirteen day study tended to have a sinilar supply to demand ratio over the thirteen day study
period. These values were lower than those previously found in an older banded group of lambs in all three study states (2).

Table II gives the mean and standard deviation of the mean for the transfiltered $4-12$ micron tran states. In general, the mid wall of the right ventricle had a higher flow than both the subendocardial (inner) and subepicardial (outer) layers. There group.

\section{DISCUSSION}

The results of this study are of interest from two aspects: First, the finding of reduced cardiac functional reserve in lambs with persistent right ventricular hypertension; and second, the finding of substantial coronary

The limitations and criticisms of conventional ventricular function curves in intact experimental animals and man are applicable to this study. Specifi cally, increases in preload induced by volume infusion may also change afterload and possibly contractile state, thereby producing an influence on myocardial performance (cardiac output) in addition to that of preload or the FrankStarling mechanism. The use of atrial pressure to estimate end diastolic fiber length or ventricular geometry assumes that diastolic compliance is similar
between banded and unbanded groups and this may not be so. However, if ventricetween banded and unbanded groups and this may not be so. However, if ventricular compliance were decreased in the banded lambs, this would be an explana-
tion for impaired right and/or left ventricular function. There are two addition for impaired right and/or left ventricular function. There are two additional potential sources of error. One is the possibility that the foramen
ovale was patent resulting in an intra-atrial shunt. This would cause the ovale was patent resulting in an intra-atrial shunt. This would cause the
right and left ventricular outputs to differ, and if the shunt was left to right cause an error in the microsphere cardiac output measurements. However, we did not identify a patent foramen ovale in any lamb. Further, left atrial pressure was higher than right in most states in all lambs. A second possible
source of error was the use of the isoproterenol stress state prior to dextran infusion.

Our finding of impaired right ventricular function in the banded lambs in the early neonatal period is similar to that of Heymann and Rudolph (11) in normal fetal lambs in utero. However, the relatively normal right ventricular function curves in the control group suggests that impaired fetal right ventricular function is corrected during the neonatal period. Improvement in right ventricular functional reserve in nomal lambs may in part be due to the fall in right ventricular pressure at birth. The impaired right ventricular function in the banded group in our study is in contrast to relatively nomal right ventricular function in lambs studied 6 to 12 weeks after pulmonary
artery banding (2). Comparison of right ventricular stroke work and right atrial pressures before and after dextran in our previous study (2) shows that 
the older banded lambs had a slightly steeper right ventricular function curve than the older control lambs and than the control lambs in this study. The age at which measurements were made in the present study (4-17 days) is within the "injury phase" described by Meerson et. al. (17), whereas the older lambs (2) were in the compensated or stable hypertrophy period (17). This is consistent with the concept that ventricular function is impaired during the injury period of myocardial hypertrophy, but relatively normal during the stable state (17). Further, this suggests that maintenance of right ventricular afterload after birth is not just a continuance of the neonatal state, but an increased stres on the right ventricle. Closure of the foramen ovale after birth eliminates the neonatal right to left shunt, thereby increasing right ventricular stroke volume, an increase in right ventricular stress. This coupled with maintenance of right ventricular afterload in the post-natal period may produce a right ventricular stress state in excess of the fetal level. A final, although unlikely, possibility for the impaired ventricular function is that the biochemical stimulus for right ventricular growth was altered during the 24 or 48 hour period between birth and banding.

The finding that left ventricular function was impaired in the banded but not the control group suggests that persistent right ventricular hypertension in the early neonatal period has an effect on left ventricular function. It has been shown that pulmonary artery banding is associated with changes in left ventricular structure (13), late left ventricular hypertrophy (14), and increased left ventricular connective tissue $(18)$. However, comparison of left ventricular stroke work and left atrial pressures before and after dextran in our previous study (2) shows that the older control and banded lambs had left ventricular function curves similar to the control lambs in this study. There is, however, no information on left ventricular biochemical or functiona changes eariy after production of right ventricular hypertension.

The decrease in right ventricular weight to total body weight ratio in the control lambs in the first two and one-half weeks of life as compared to the maintenance of a near constant weight ratio in the banded lambs suggests that persistent right ventricular hypertension in the post natal period main tains stimulus to right ventricular growth not present in nomal lambs. The edema because the right ventricular wet to dry weight ratios were not different.

Right ventricular coronary flow per unit weight was lower than septal and left ventricular flow in the control group at rest, as is usually found in older animals $(5,7,10,12)$. Conversely, right ventricular flow per unit weight was equal to or greater than septal and left ventricular flow in the banded lambs at rest. Further, resting right ventricular flow in banded lambs was significantiy higher than in control lambs. This suggests an increase in group and is consistent with group, and is consistent with calculated higher values of right ventricular wall stress in the banded group (table I). However, the ratio of right to left ventricular oxygen supply to demand ratio was similar in the control and banded
groups and, in general, lower than that seen in banded older lambs (2). We have found the ratio of right to left ventricular oxygen supply to demand to be more sensitive to differences between banded and control groups than values for
the right ventricle alone because the ratio method removes variability common to both ventricles such as heart rate, arterial blood oxygen content and the variability of the microsphere arterial reference sample method (2). During isoproterenol infusion regional flows to all three regions of the heart increased from resting levels in all control lambs and in 4 of 5 banded lambs, demonstrating resting coronary vascular reserve in both groups. Banded lamb number 2 was clearly in right ventricular failure, probably from too severe a constriction of the pulmonary artery, and had a very high resting right ventricular myocardial blood flow which did not change with stress. The remainder of the banded as well as the control lambs had a decrease in right ventricular coronary vascular resistance in both the isoproterenol and dextran stress states. This coupled with the similarity of the transmural distribution of right ventricular flow in both groups makes the possibility of impaired right ventricular function because of inadequate coronary blood flow seem unlikely. However, since we did not test for further right ventricular coronary vascular reserve in the dextran stress states we cannot be certain that coronary flow was not maximal and thus function impaired by inadequate oxygen supply.
REFERENCES

1. Archie. J.P., Fixler, D.E., Ullyot, D.J., and Hoffman, J.l.E.: Measurement of cardiac output with and organ trapping of radioactive microspheres. J. Appl. Physiol. 35:148-154, 1973.

2. Archie, J.P., Fixler, D.E., Uliyot, D.J., Buckberg, G.D., and Hoffman, J.I.E.: Regional myocardial blood flow in tranquilized lambs with right ventricular hypertrophy. Circ. Res. 34:143-154, 1974.

3. Aukland, K., Kijl, F., and Kjekshus, J.: Relationship between ventricular RV pressures and right and left ventricular myocardial blood flows. Acta. Physiol. Scand. 70:116-126, 1967.

4. Buckberg, G.D. Luck, J.C., Payne, D.B., Hoffman, J.I.E., Archie, J.P. . radioactive microspheres. J. Appl. Physiol. 31:598-604, 1971.

5. Buckberg, G.D., Fixier, D.E., Archie, J.P., and Hoffman, J.I.E.: Experimental subendocardial ischemia in dogs with nomal coronary arteries. Circ. Res. 30:67-81, 1972.

6. Cross, C.E.: Right ventricular pressure and coronary flow. Am. J. Physiol. 202:12-16, 1962 .

7. Domenech, R.J., Hoffman, J.I.E., Noble, M.I.M., Saunders, K.B., Henson, J.R., and Subijanto, S.: Total and regional coronary blood flow measured by radioactive microspheres in conscious and anesthetized dogs. Circ. Res. 25:581-596, 1969

8. Downing, S. E., Tainer, N.S., and Gardner, T.H.: Ventricular function in

the newborn Iamb. Am. J. Physiol. 208:931-937, 1965 . Downing, S.E. Lee, J.C. Taylor, J.F.N., and Hailoran, k: Influence of norepinephrine and digitalis on myocardial oxygen consumption in the newborn lamb. Circ. Res. 32:471-479, 1973.

10. Fixler, D.E., Archie, J.P., Uliyot, D.J.. Buckberg, G.D., and Hoffman, J.1.E.: Effect of acute right ventricular systolic hypertension on regional myocardial blood flow in dogs. Am. Heart J. 85: 491-500, 1973.

11. Heymann, M.A. and Rudolph, A.M.: Effects of increasing preload on right ventricular output in fetal lambs in utero. Circ. VII and VIII (Supplement

12. Hoffman, J.I. E., Buckberg, G.D., Fixler, D.E., and Archie, J.P.: Regional flow in the right and left ventricular free walls and septum during tachycar
dia, aortic constriction and arterio-venous fistulas. In Myocardial Blood
Flow in Man. A. Maseri (ed.). Minerva Medica, 1972, p. 65-78.

Flow in Man. A. Maseri (ed.), Minerva Medica, 1972, p. 65-78. cular celi and saramere lengths after banding the pulmonary artery. Circ. Res.

14:704-710, 1969. cular volume, compliance, and mass in the normal and pulmonary arterial banded 15 . Leart. Cardiovascular Res, 6:187-198, 1972.

flow and fow and myocardial metabolism in newborn lamb:

demia. Am. W. Physiol. $224: 1381-1387$, 1973 . 16. Love. W.D. and O'Meallie, L.P.: Increase in coronary blood flow to the load. J. Lab. Clinc. Med. 62:72-77. 1963.

17. Meerson, F.Z., Alefhina, G.M., Aleksandrov, P.N. and Bazardjan, A.J.: Dynamics of nucleic acid and protein systhesis of the myocardium in compensatory hyperfunction and hypertrophy of the heart. Amer. J. Cardiol. 22:237248. 1968.

18. Spann, J.F., Sonnenblick, E.H., Harris, E.D. and Buccino, R.A.: Connective tissue of the hypertrophied heart. In Cardiac Hypertrophy. Alpert $N$

(ed). New York. Academic Press, 1971, pp. 141-145.

20. Supported in part by Program Project Grant HE 06285 from the National Heart, Lung, and Blood Institute. Or. Archie was supported by NIH Grant
T01 DMO 1924-03, Dr. Fixler by NIH Special Fellowship 5 F03-HE-43, 472-02. 1. Request for reprints should be addressed to: Joseph P. Archie. Jr...M.D., Department of Surgery, Carraway Methodist Medical Center and Norwood Clinic.

161525 th Street North. Birmingham. Alabama 35234.

22. Received for publication February $14,1977$.
23 . Accepted for publication April 5, 1977.

TABLE I. Hemodynamics in Control and Banded Lambs in Resting ( $R$ ) Isoproterenol ( $I)$ and Two Dextran $\left(D_{1}, O_{2}\right)$ States

\begin{tabular}{|c|c|c|c|c|c|c|c|c|c|c|c|c|c|c|c|c|c|c|c|c|c|c|c|c|c|c|}
\hline \multirow{2}{*}{ Control } & \multirow{2}{*}{$\begin{array}{c}\text { Age } \\
\text { (days) }\end{array}$} & \multirow{2}{*}{$\begin{array}{l}\text { Body } \\
\text { Weight } \\
(\mathrm{kg})\end{array}$} & \multirow[t]{2}{*}{$\begin{array}{l}\text { Hemoglobin } \\
(\mathrm{mg} / \mathrm{dl})\end{array}$} & \multicolumn{4}{|c|}{$\underset{\text { (torr) }}{\text { Arterial }} \mathrm{PO}_{2}$} & \multicolumn{4}{|c|}{$\begin{array}{l}\text { Heart Rate } \\
\text { (beats/min) }\end{array}$} & \multicolumn{3}{|c|}{$\begin{array}{l}\text { Systolic LV } \\
\text { Pressure } \\
\text { (mmHg) }\end{array}$} & \multicolumn{4}{|c|}{$\begin{array}{c}\text { Systolic RV } \\
\text { Pressure } \\
\text { (rmHg) } \\
\end{array}$} & \multicolumn{4}{|c|}{$\begin{array}{l}\text { Cardiac } \\
\text { Index } \\
\left(\mathrm{ml}^{-} \cdot \mathrm{min}^{-1} \cdot \mathrm{kg}^{-1}\right)\end{array}$} & \multicolumn{4}{|c|}{$\begin{array}{l}\text { RV Wall } \\
\text { Stress } \\
\left.\text { (torr } \times 10^{3}\right)\end{array}$} \\
\hline & & & & $\stackrel{R}{-}$ & I & o & $\underline{\mathrm{O}_{2}}$ & $\underline{R}$ & I & $\underline{D_{1}}$ & $\underline{\mathrm{O}_{2}}$ & $\stackrel{R}{-}$ & $1-\underline{D_{1}}$ & $\underline{\mathrm{D}_{2}}$ & $\stackrel{R}{-}$ & $\begin{array}{l}\mathrm{I} \\
-\end{array}$ & $\underline{D_{1}}$ & $\underline{\mathrm{D}_{2}}$ & $\stackrel{\mathrm{R}}{\rightarrow}$ & I & $0_{1}$ & $\mathrm{O}_{2}$ & $\begin{array}{l}R \\
-\end{array}$ & 1 & $D_{1}$ & $\underline{\mathrm{O}_{2}}$ \\
\hline 1 & 5 & 4.50 & 9.1 & 66 & - & - & - & 240 & - & - & - & 93 & - - & - & 35 & - & - & - & 349 & - & - & - & 20.3 & - & - & - \\
\hline 2 & 7 & 6.70 & 10.2 & 80 & 80 & 80 & 81 & 225 & 342 & 220 & 220 & 92 & $79 \quad 94$ & 94 & 33 & 66 & 43 & 43 & 267 & 342 & 337 & 282 & 25.3 & 50.6 & 33.0 & 33.0 \\
\hline 3 & 11 & 5.65 & 11.0 & 75 & 81 & 72 & 62 & 285 & 360 & 270 & 248 & 90 & $86 \quad 112$ & 98 & 24 & 25 & 50 & 46 & 276 & 407 & 315 & 322 & 14.8 & 15.5 & 30.9 & 28.5 \\
\hline 4 & 15 & 7.57 & 9.4 & 57 & 84 & 98 & 89 & 180 & 315 & 240 & 270 & 115 & $97 \quad 115$ & 120 & 46 & 35 & 47 & 38 & 128 & 254 & 333 & 322 & 40.8 & 31.0 & 41.7 & 33.7 \\
\hline 5 & 18 & 8.10 & 10.5 & 76 & 72 & 75 & 78 & 215 & 320 & 232 & 215 & 105 & 108107 & 103 & 26 & 50 & 41 & 38 & 215 & 254 & 353 & 279 & 24.7 & 47.5 & 38.9 & 36.1 \\
\hline \multicolumn{27}{|l|}{ Banded } \\
\hline 1 & 5 & 4.88 & 9.9 & 80 & 92 & 77 & 73 & 200 & 330 & 160 & 276 & 93 & 91120 & 105 & 50 & 67 & 66 & 78 & 326 & 314 & 299 & 393 & 34.1 & 45.7 & 45.0 & 53.2 \\
\hline 2 & 8 & 5.00 & 7.9 & 64 & 67 & 69 & 71 & 230 & 255 & 235 & 150 & 65 & 6268 & 63 & 90 & 87 & 92 & 66 & 298 & 398 & 258 & 166 & 45.1 & 43.6 & 46.13 & 33.1 \\
\hline 3 & 10 & 5.25 & 11.4 & 80 & 77 & 66 & 69 & 130 & 330 & 180 & 156 & 100 & $100 \quad 125$ & 123 & 60 & 70 & 67 & 67 & 210 & 339 & 253 & 210 & 32.2 & 37.5 & 35.93 & 35.9 \\
\hline 4 & 13 & 5.52 & 11.6 & 67 & 75 & 64 & - & 195 & 270 & 246 & - & 115 & 90105 & - & 77 & 65 & 65 & 85 & 279 & 272 & 272 & 357 & 45.4 & $38.3=$ & 50.1 & - \\
\hline 5 & 18 & 8.14 & 8.8 & 79 & 67 & 72 & 74 & 150 & 280 & 160 & 165 & $\begin{array}{l}107 \\
86\end{array}$ & 94125 & 125 & 85 & 92 & 88 & 85 & 307 & 251 & 233 & 305 & 51.1 & 44.5 & 42.5 & 41.1 \\
\hline
\end{tabular}



IABLE 11. Right Ventricular Transmural Distribution of
Blood Flow

Resting State Control Banded

$\begin{array}{lll}\text { I } & 0.995 \pm 0.0300 & 0.953 \pm 0.0616 \\ M & 1.123 \pm 0.0286 & 1.127 \pm 0.0448 \\ 0 & 1.009 \pm 0.0720 & 0.960 \pm 0.0289\end{array}$

Isoproterenol State

$\begin{array}{lll}\text { I } & 0.913 \pm 0.0436 & 0.929 \pm 0.0754 \\ M & 1.224 \pm 0.0301 & 1.130 \pm 0.0424 \\ 0 & 0.951 \pm 0.0370 & 0.981 \pm 0.0494\end{array}$

Dextran State

$\begin{array}{lll}\text { I } & 0.926 \pm 0.0583 & 0.935 \pm 0.0460 \\ M & 1.172 \pm 0.0167 & 1.167 \pm 0.0321 \\ 0 & 0.935 \pm 0.0820 & 0.953 \pm 0.0333\end{array}$

All values are mean \pm 1 SDM and are obtained by dividing the flow per unit weight for the region ( $I$ is inner. $M$ is mid and 0 is outer wall) by the flow per gram for the whole right ventricle $(I+M+0)$.

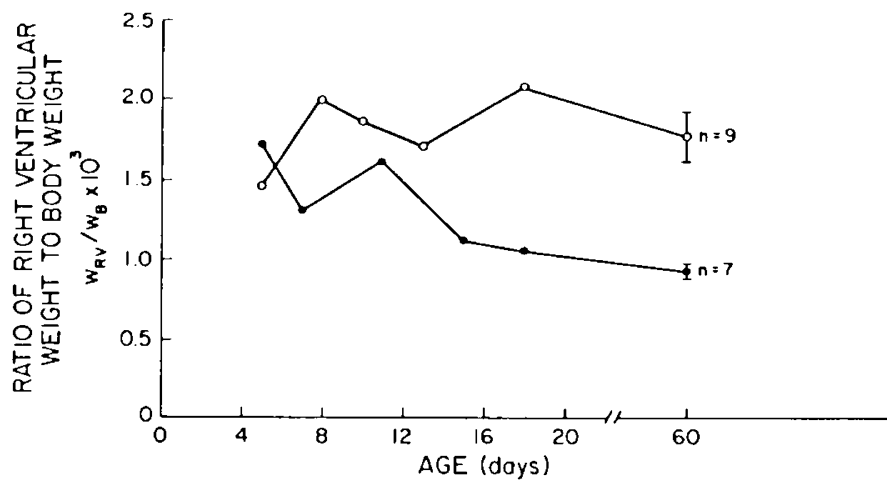

Figure 1. The ratio of right ventricular free wall weight to body weight $\left(W_{R V} / W_{B}\right)$ for control $(\cdot)$ and banded $(0)$ lambs at their age when studied. The values on the right are for (mean \pm 2 SDM) comparable groups at a mean age of 60 days (2).

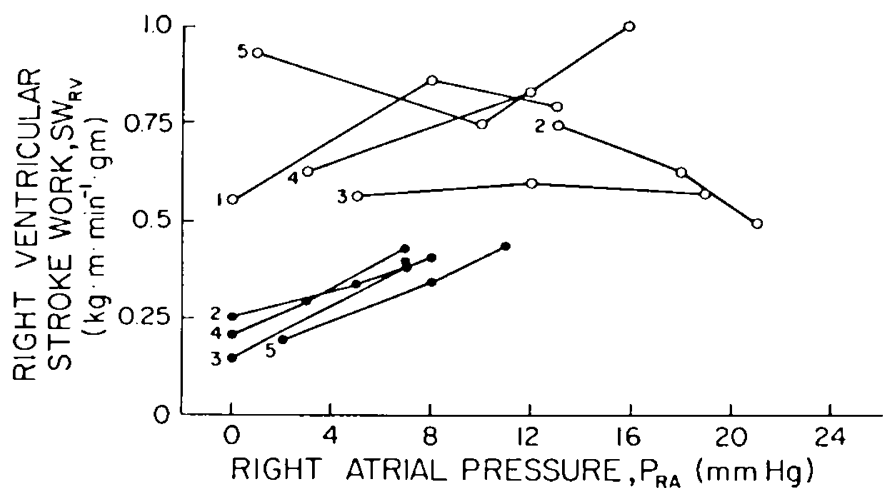

Figure 2. Right ventricular stroke work $\left(S W_{R V}\right)$ versus mean right atrial pressure $\left(P_{\mathrm{RA}}\right)$ for the control $(\cdot)$ and banded $(0)$ lambs at rest and during dextran infusion. The numbers identify each lamb as per Table 1 .

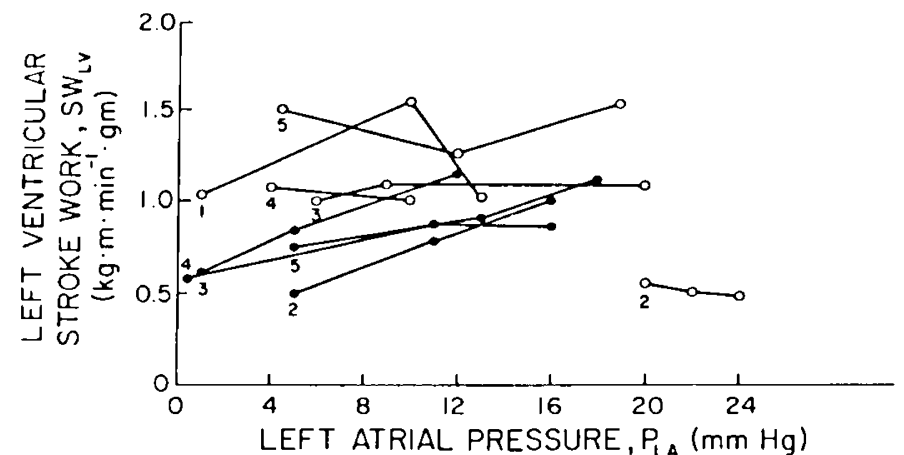

Figure 3. Left ventricular stroke work $\left(S W_{L V}\right)$ versus mean left atrial pressure

$\left(P_{L A}\right)$. Symbols and protocol per figure 2.

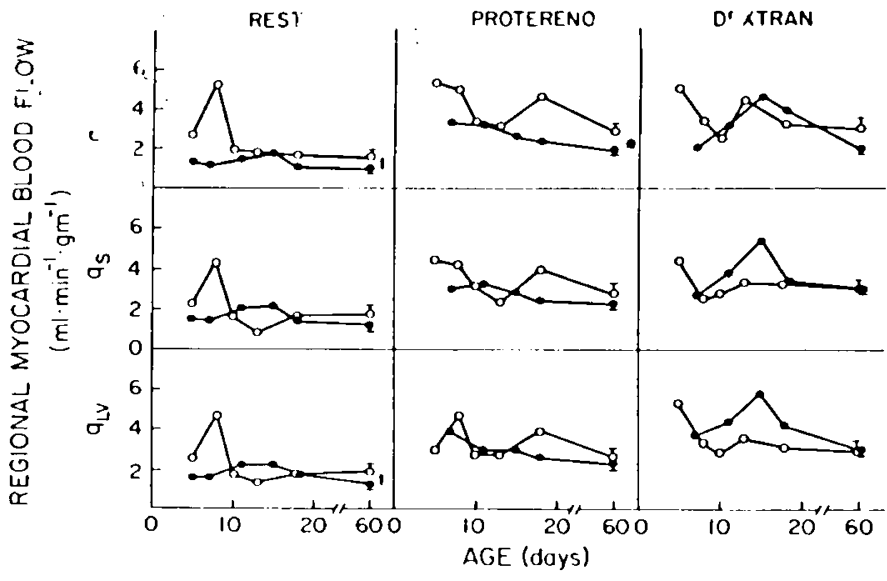

Figure 4. Regional myocardial blood flow to free wall right ventricle $\left(q_{R V}\right)$, septum $\left(q_{S}\right)$ and free wall left ventricle $\left(q_{L V}\right)$ for control $(\cdot)$ and banded $(0)$

lambs during three study states. Values to right of each panel are (mean \pm 2 SDM) flows for comparable groups at a mean age of 60 days (2) (t $0.05<p<$ $0.05)$.

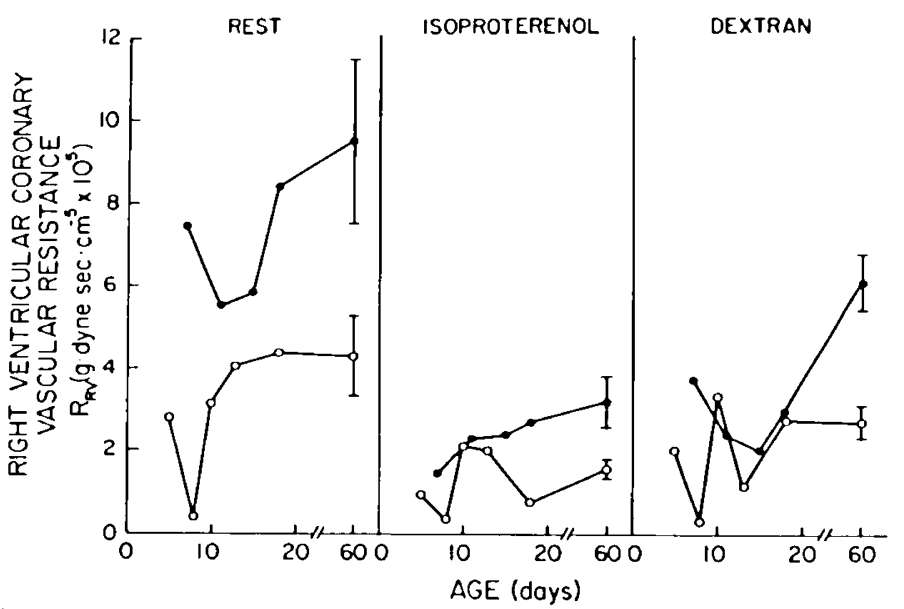

Figure 5. Right ventricular coronary vascular resistance for control $(\cdot)$ and (mean SDM) resistance for comparable groups at a mean age of 60 days (2) (** $p<$

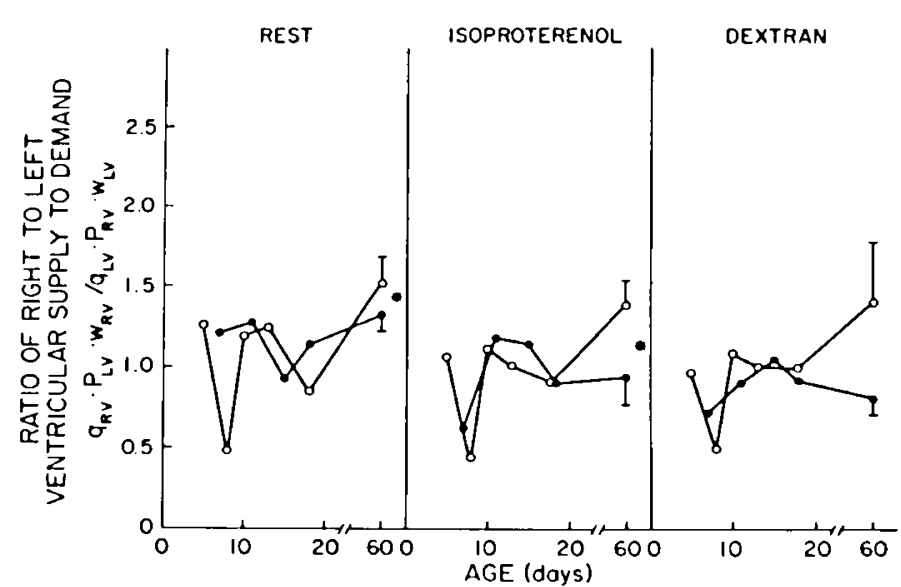

Figure 6. Estimate of right ventricular oxygen supply to demand ratio at age of study. Values on right of each panel are (mean \pm 2 SDM) ratios for comparable group at a mean age of 60 days (2) $\left({ }^{\star} p<0.05\right)$ 